\title{
Sub-System Based Reliability Assessment for Distribution Transformer
}

\author{
Md Rakib Ur Rahman and Visvakumar Aravinthan \\ Dept. of Electrical Engineering and Computer Science Wichita State University \\ Wichita, Kansas, USA \\ rahman.mdrakibur@gmail.com
}

\begin{abstract}
Implementation of Smart Grid into the power system has made our grid more robust and reliable. Due to integration of two-way, real time communication it is possible to monitor equipment through sensors. Continuous monitoring will help to predict the state of the equipment. Due to this fact and also to ensure the system performance, time based maintenance can be replaced by condition or reliability based maintenance. Contribution of this work is to identify the appropriate standards for to be used for the transformer subcomponents and develop appropriate Weibull distribution parameters for each subcomponent for a modified series-parallel topology of distribution transformer. This modification is done based on the available measurements and standards. Using the developed reliability model, Monte Carlo simulation was performed to evaluate the behavior of these parameters.
\end{abstract}

Keywords-smart grid, reliability, Weibull distribution, condition based maintenance

\section{INTRODUCTION}

Transmission and Distribution Electric utility businesses are facing challenges of sectoral reforms, more stringent regulatory norms, increasing customer demands, rising need for customer satisfaction, and growing system reliability requirements. Performance of the distribution system is now a growing concern not only for the utility but also for the regulators. Statistics shows, on average $80 \%$ of the interruptions are attributed to failures in the distribution system.

To ensure maximum performance the regulators came up with condition based maintenance instead of traditional time based maintenance which will help regulators to predict any premature failure. But condition based maintenance got some drawbacks too. Since our distribution system operates in uncertain environment so modeling the system requires a probabilistic approach [1]. Lack of failure information and unavailability of data made it hard to get an accurate model. The rest of the paper is organized as follows: Background and Literature review have been discussed in Section II. Methodology and steps for calculating Weibull parameters have been given for different subsystem with range of use in section III. Section IV includes the numerical analysis with modified series parallel topology.
System reliability was calculated for best and worst case and with/without the weights. Discussion and conclusion is given in section V. Suggestions for future work is included in section VI.

\section{BACKGROUND AND LITERATURE REVIEW}

The first distribution reliability model was developed by Electric Power Research Institute (EPRI) in 1978 [2], was not widely used due to conservative design and maintenance standards. In 1990, a new procedure was described for predicting the failure of the transformer to quantify the expected impacts on serving reliability [3]. The method was particularly well adapted to failure frequency forecasts and outage predictions for large, expensive apparatus for which accelerated life testing is not appropriate and for which historical failure data is limited because of an inherent low failure rates. The procedure made the use of a systematic method for combining only the most credible features of engineering models with real world experience and had been referred to as both calibrated engineering and Combined Analysis (CA). Weibull distribution was used in this process but required calibration to adjust the failure rate.

A study presented in [4] analyzed the condition of the transformer based on field assessments mainly focusing on identifying the failure moods of a transformer and tried to grade the levels of each condition.

When system reliability models typically used average equipment failure rates or the assume the behavior of the equipment from field assessments, a study presented in [5] showed a new method of customizing failure rates using equipment inspection data. That allowed available inspection information to be reflected in interruption distributions rather than mean values. Later that model was tested using reclosers in [6] and they developed a procedure to determine the worst performing components based on these failure rates.

The new approach showed some promising result but it had some drawbacks too. The failure rate was modeled as exponential, a nonstandard random distribution model. But not all the components can have exponential failure rates. Also, the 
weighting technique was not justified well enough. It was really based on assumptions and field data where the scenario can be different too. So, the model depended highly on calibration.

A former Wichita State University student established a procedure to identify more realistic criteria for component assessment using manufacturer data [7], standards, guidelines, and historical failure data. He prepared a condition assessment sheet same as [5] with four different categories and tried to find out the reliability using scoring and weighting techniques which was later improved in [8] for some criteria to identify the worst performing components of a transformer using Weibull distribution. Inspired from the work presented in [8] this paper focuses on the sub-component based reliability using Weibull distribution using the weighting techniques. The conditions he developed for power transformers are given in "Fig 1" [1]

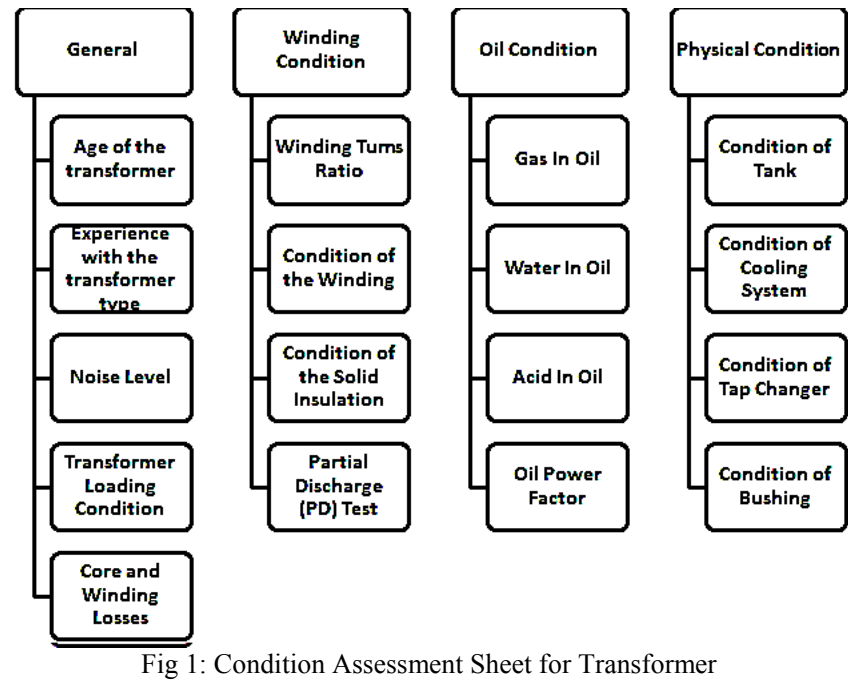

\section{Methodology AND Steps For CALCUlating WeIBUll PARAMETERS}

This paper discusses the impact of sub-components on the transformers reliability. Among the 17 sub-components, 10 were discussed and analyzed in this paper.

\section{A. Component Reliability Assessment Procedure}

The following flowchart describes the general procedure used in this work.

Step 1: Determine the appropriate standards and the possible failure subsystems

The model developed in [7] is used as the reference point. The system developed in [7] which do not have any specific standards nor which were not measurable were eliminated in this work. The sub-components that were used in this work are: Age of the transformer: Transformer age has a significant effect of the condition of the transformer. Historical data from [8] was used to determine the behavior of the transformer.

Noise level: The NEMA Standard 20-2014 is used to determine the condition of the transformer.

Core and winding losses: IEEE Standard C.57.123 was used in this work to determine the impact of core and winding losses on the transformer life presented in [9].
Condition of Solid Insulation: Condition of the solid insulation can be tested using the insulation level of the material. The methodology is provided in [10] could be used to determine the insulation condition.

Partial discharge: IEEE Standard C57.113-1991 provides the condition basement and testing of partial discharge [11].

Gas in oil: IEEE Std. C57.104-2008 provided in [1] recommends the allowable gases in a transformer as the parts per million.

Water in oil: Based on IEEE Std. C57.106-1977 the impact of water in oil to be determined. A report presented in [13], [14] and [15] were used to determine the level of moisture in oil.

Acid in oil: The impact of acid in oil needs to be determined based on [16].

Oil Power Factor: IEEE C57.106-1991 is used to test the power factor in oil and its effects described in [16] and [17].

Step 2: Determining the Weibull distribution parameters

The two-parameter model for Weibull distribution is used and the shape parameter $(\beta)$ and scale parameter $(\alpha)$ were determined using the following methods.

\section{a) Reliability from historical data:}

In this case sufficient historic data is available. The following relationship [1] is used to determine the shape and scale parameter,

$$
\log _{10} h(r)=\log _{10}\left(\frac{\beta}{\alpha^{\beta}}\right)+(\beta-1) \log _{10}(r)
$$

where, $h(r)$ is the hazard rate computed based on the factor $r$. factor $r$ is the measurement available for the parameter computation. The least square method is used to find the slope and $y$ axis intercept to plot the hazard rate from the historical data. From the graph, we can determine the value of $y$ and $x$. Based on the above equation the Weibull parameters $\alpha$ (scale parameter) and $\beta$ (shape parameter) are estimated.

\section{b) Reliability from guidelines or standards}

Based on the standards or guidelines the best and worst case of each subsystem can be determined. Once this is available, this can be translated into reliability. Best case would have high reliability (close to one) and the worst case will have lower reliability (close to zero). This information can be used in (2) [1] to determine the shape and scale parameters.

$$
\ln \left(\ln \left(\frac{1}{R(x)}\right)\right)=\beta \ln x-\beta \ln \alpha
$$

Where $R(x)$ is the reliability, if the condition is good then we have used 0.95 and if the condition is bad, $R(x)$ is considered 0.10. $x$ is the point where reliability is considered and $\alpha$ and $\beta$ are the Weibull parameters.

\section{B. Sub-system Weibull Parameters}

Based on the modeling provided in the previous section the Weibull parameters are determined. Table I shows the range for which the parameters have been calculated.

a) Weibull Parameters and Range: 
Using the historical data and standards, the Weibull Parameters have been calculated based on the equation (1) and equation (2). Range for the sub-components has been provided in Table I. Column two describes the range of each subcomponent for which $\alpha$ and $\beta$ have been calculated.

TABLE I. WeIBUll PARAMETERS AND RANGE

\begin{tabular}{|c|c|c|c|}
\hline Criteria & Range & $\boldsymbol{\alpha}$ & $\boldsymbol{\beta}$ \\
\hline $\begin{array}{c}\text { Age of the } \\
\text { Transformer }\end{array}$ & - & 23.35 & 4.92 \\
\hline Noise & $47-60 \mathrm{db}$ & 56.8722 & 15.5785 \\
\hline $\begin{array}{c}\text { Core and } \\
\text { winding } \\
\text { losses }\end{array}$ & $\begin{array}{c}\text { Max tolerance of } \\
6 \% \text { total loss }\end{array}$ & 0.0405 & 2.1232 \\
\hline $\begin{array}{c}\text { Solid } \\
\text { Insulation }\end{array}$ & $\begin{array}{c}200-1200 \\
\text { Insulation level } \\
(\mathrm{dp})\end{array}$ & 650.2487 & 1.5865 \\
\hline $\begin{array}{c}\text { Partial } \\
\text { Discharge test }\end{array}$ & $10-1000 \mathrm{pC}$ & 364.3539 & 0.8261 \\
\hline Gas in Oil & $0.7-4.6 \mathrm{ppm}$ & 3.0444 & 2.0206 \\
\hline Water in Oil & $0-20 \%$ & 0.1037 & 1.2699 \\
\hline Acid in Oil & $0.010-1.50 \mathrm{NN}$ & 0.5000 & 0.7592 \\
\hline Oil Power & $0.5-2 \%$ & 0.0148 & 2.7442 \\
\hline Factor & & &
\end{tabular}

\section{System Reliability}

Based on the relevance to failure a series-parallel topology for transformer reliability computation was determined in [1]. Modified series parallel topology is used in this work too. The modified model is given in "Fig. 2."

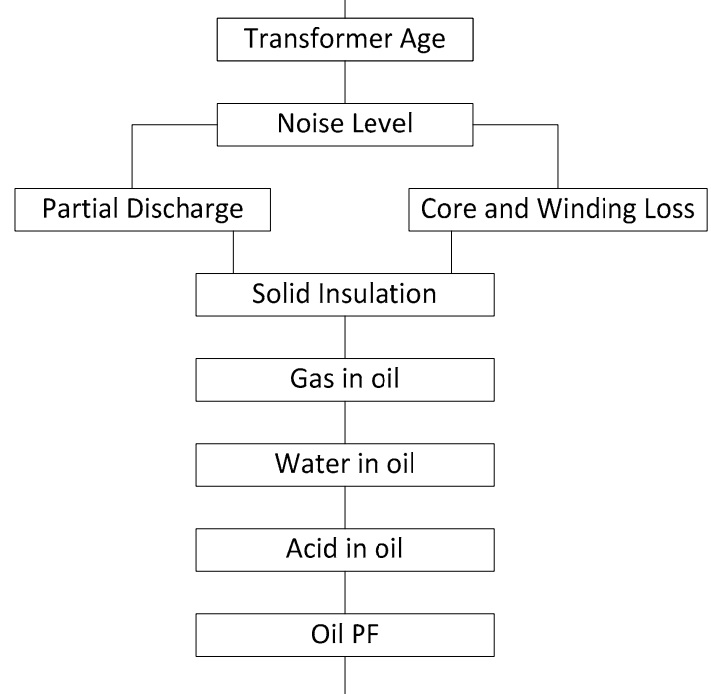

Fig. 2: Modified Series Parallel Topology

\section{NUMERICAL ANALYSIS}

Based on the modified series parallel topology, the reliability of each sub-component has been analyzed. Example includes best and worst case scenario and later the weighting technique has been introduced to check the improve reliability condition of each sub-component and the system as well.
The first part shows a simple example case of factors used in this work and the reliability computation. In the first case the random values are taken which are in the good range. The system reliability is shown in Table II and the poor condition is shown in Table III.

As shown in Table II when the condition of the subcomponents is good, the system reliability is higher. On the other hand, when the subcomponents have poor condition the system reliability is lower as shown in Table III.

Furthermore, in Table III it should be noted that the acid is in very poor condition. Level determines the point of the subcomponent when reliability is calculated. Finally, system reliability was calculated based of modified series parallel topology. Based on each subcomponent good condition, the system is $63 \%$ reliable.

TABLE II. A Good CASE RELIABILITy COMPUTATION

\begin{tabular}{|c|c|c|}
\hline Factor & Level (x) & $\begin{array}{c}\text { Subcomponent } \\
\text { Reliability(Rx) }\end{array}$ \\
\hline Age & 5 & 0.9994 \\
\hline Noise level & 45 & 0.9742 \\
\hline Partial discharge & 20 & 0.9130 \\
\hline Winding loss & 0.010 & 0.9499 \\
\hline $\begin{array}{c}\text { Insulation level of } \\
\text { the paper }\end{array}$ & 150 & 0.9070 \\
\hline Gas in oil & 0.600 & 0.9631 \\
\hline Water in oil & 0.020 & 0.8836 \\
\hline Acid in oil & 0.020 & 0.9168 \\
\hline Oil PF & 0.006 & 0.9194 \\
\hline \multicolumn{2}{|c|}{ System Reliability } & 0.63094 \\
\hline \multicolumn{2}{|l}{}
\end{tabular}

TABLE III. A POOR CASE RELIABILITY COMPUTATION

\begin{tabular}{|c|c|c|}
\hline Factor & Level & $\begin{array}{c}\text { Subcomponent } \\
\text { Reliability }\end{array}$ \\
\hline Time & 15 & 0.89284 \\
\hline Noise level & 50 & 0.87416 \\
\hline Partial discharge & 600 & 0.22092 \\
\hline Winding loss & 0.0400 & 0.37758 \\
\hline $\begin{array}{c}\text { Insulation level of the } \\
\text { paper }\end{array}$ & 550 & 0.46453 \\
\hline Gas in oil & 3 & 0.37879 \\
\hline Water in oil & 0.0800 & 0.48710 \\
\hline Acid in oil & 0.9500 & 0.19633 \\
\hline Oil PF & 0.0100 & 0.71105 \\
\hline \multicolumn{2}{|c|}{ System Reliability } & 0.00481 \\
\hline
\end{tabular}

To evaluate the behavior of each subsystem a Monte-Carlo simulation was used. In each case one of the factors is changed from good to bad while keeping the randomly selected the condition of other values constant. The procedure is repeated for 10 different cases where the values of other factors are changed and kept constant for each case. The results are shown below.

a) Analysis of the Simulation done for 1000 trials: 
"Fig. 3" shows the relationship how increase of aging factor can change the whole reliability. For the year span of 30 the reliability changes after 15 years. From the beginning of its operational time, until it reaches 15 years in operation, the reliability of the transformer was maintaining a constant value until it reaches age 15 and the reliability follows a decreasing pattern with increase of age of the transformer. Here all the other factors such as noise, loading, insulation etc. are taken to be a constant value while the age of the transformer was randomized in-between 30 years to see how it affects the reliability of the system.

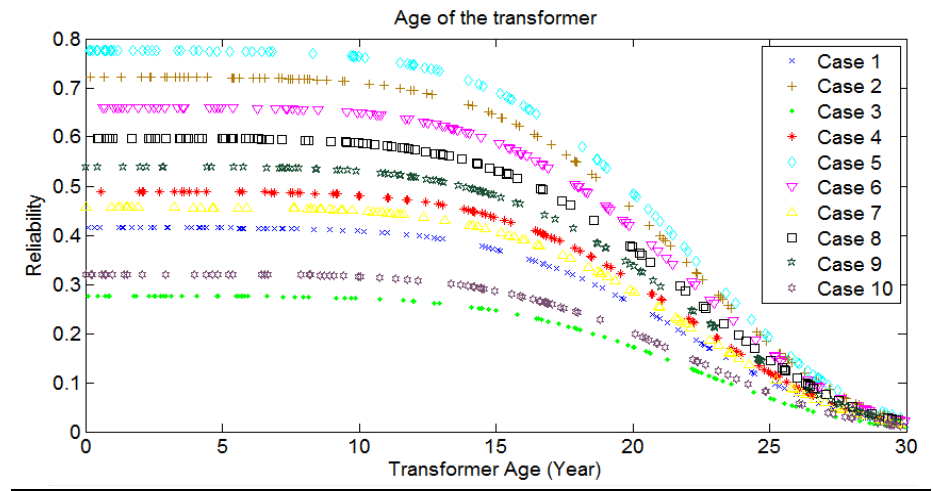

Fig. 3 Change in Transformer reliability due to age of the transformer

The same simulation was done for noise level to see the impact in reliability in "Fig. 4". Different case indicates the different set of values where each time noise is randomly varied within the range provided keeping the other factors constant.

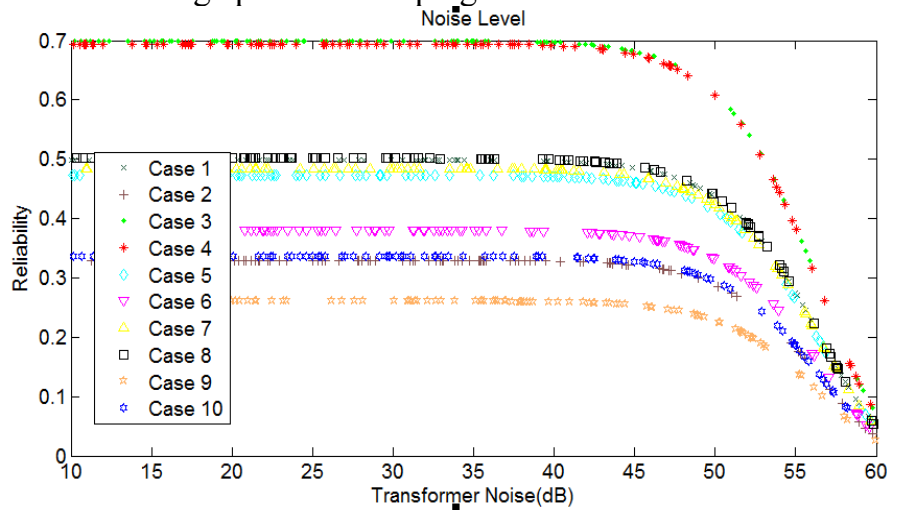

Fig. 4: Analysis of the simulation for 1000 trials considering the noise level

"Fig.4" Shows a promising a result. It is clear that the transformer as a whole system is quite reliable in between 0-45 $\mathrm{dB}$. The reliability decreases with increase in noise when noise reaches $45 \mathrm{~dB}$. According to standards the audible sound level should be ranging from 47 to $60 \mathrm{~dB}$. From the figure it is clear that, for the sound level up to $40 \mathrm{~dB}$, the reliability of the transformer is maintaining a good value but after the noise reaches 60 , the reliability drastically falls to zero. Following two simulations are done to check the condition for a parallel sub-component.

From "Fig.5," we can see a change of reliability with increase in PD (degree of polymerization) level. But the change in reliability is not that much significant due to the other fixed constraints.

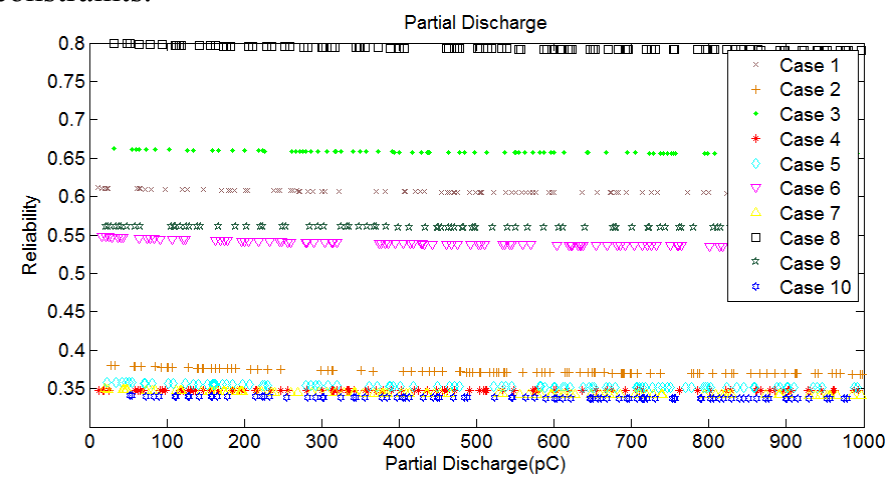

Fig.5: Impact of partial discharge test in the whole system

Since Partial discharge and core \& winding loss are parallel to each other so the impact is not that much significant on the whole system. Similar result is found for core and winding losses in "Fig.6."

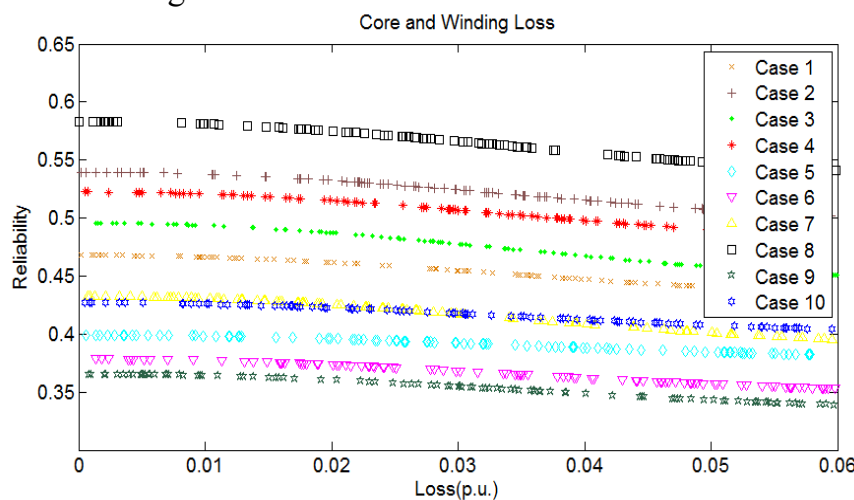

Fig. 6: Change in reliability for core \& winding losses

Similar steps are followed to see the behavioral change in transformer reliability for all other sub-components.

b) Reliability Calculations using the weighting techniques:

Even though each sub-component plays vital role for the transformers reliability but not all of them have the same impact. Say for example, loading will have a higher weight than noise level of the transformer. Considering the previous experience with that transformer type or from manufacturer information, weights can be assigned for each subcomponent.

For the simulation performed for both good and bad conditions of each sub-component, it is observed that age of the transformer and noise level tends to give a better reliability value whereas, oil condition criteria have low individual reliability value which may cause the whole system reliability to have low value. When we are considering the weights, we have to prioritized oil condition to get more weights than general and winding condition described in "Fig. 1"

For this case, Oil power factor is simulated keeping all the other sub-component constant. Behavioral change in reliability can be seen in the following figures. Since the oil condition needs more attention so oil power factor is weighted from $7 \%$ 
to $15 \%$ ("Fig. 8 "). When weight was not considered, after exceeding 0.005 p.u. the system reliability tends to fall down due to the impact of oil power factor in "Fig. 7"

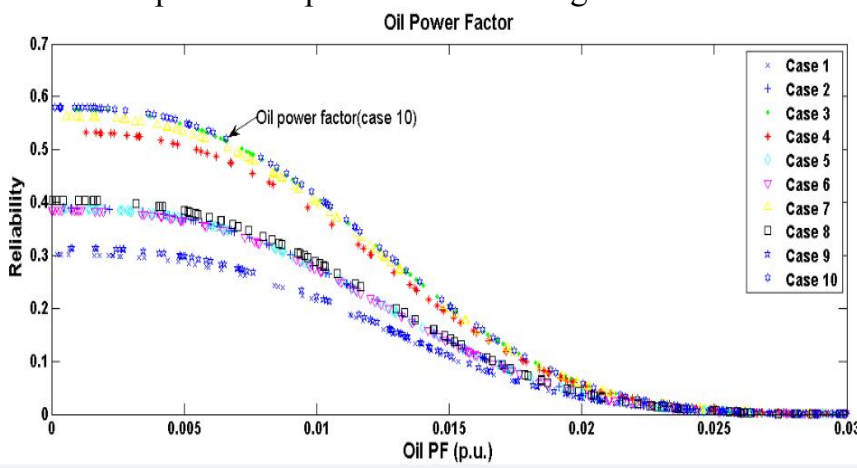

Fig. 7: Oil Power Factor without considering weights

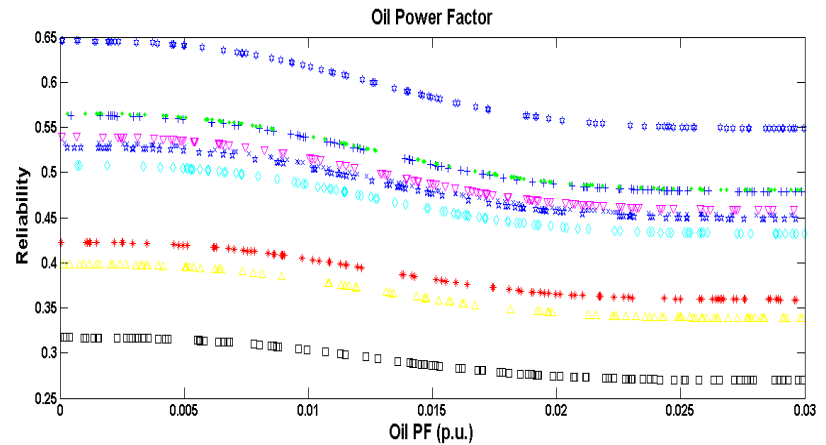

Fig. 8: Oil Power Factor considering weights

$7 \%$ to $15 \%$ weight [18] is provided depending on the level of oil power factor. Due to weights, the oil power factor shows less fluctuation and system reliability is in good shape when other sub-components are kept constant in "Fig. 8". Same procedure was followed to all Oil condition criteria. Based on each sub-components reliability weight can be assigned to get better system reliability.

\section{DISCUSSION AND CONCLUSION}

This paper is focused to find out individual sub-components reliability and to find out their impact on the transformer reliability. Historical data or standards, have been considered for finding out the scale parameter $\alpha$ and shape parameter $\beta$. Using Weibull distribution with the values of $\alpha$ and $\beta$ and range of each sub-component, individual reliability has been calculated. Modified series parallel topology is used to find out the transformers reliability for a given time. Monte Carlo simulation has been performed to get a clear idea of how reliability data for each sub component stands and the systems reliability has been monitored. Weight for each criterion is considered and transformers reliability has been recalculated to check the difference. Also, experience with the transformer type is not included here. If we include the experience this may help us to get precise data.

\section{FUTURE WORK}

Extension of this work can also include Condition Scoring. For scoring, each sub-component needs weighting. Once the weighted reliability data is available, the components condition can be scored. Component Condition Score (CCS) [1] will be helpful to determine the action needs to be taken before it face any pre-mature failure.

\section{REFERENCES}

[1] Visvakumar Aravinthan, Ward Jewell, "Identifying Worst Performing Components in a Distribution System Using Weibull Distribution", IEEE 11th International Conference on Probabilistic Methods Applied to Power Systems (PMAPS), 2010 Singapore.

[2] T.D. Vismor, J.E.D Northcote-Greem, Roy Billinton, "Development of Distribution Reliability and Risk Analysis Models", Aug 1981.

[3] E.M. Gulachenski, P.M. Bsuner, "Transformer Failure Prediction Using Bayesian Analysis", IEEE Trans. on Power Systems, MVol 5. No4. Nov. 1990. Canda.

[4] V.V Sokolov, "Considerations on Power Transformer Condition - Based Maintenance", EPRI Substation Equipment Diagnosic Conference VIII, Feb, 2000 New Orleans LA.

[5] Richard E Brown, George Frimpong and H. Lee Willis. "Failure Rate Modeling Using Equipment Inspection Data", IEEE Trans. on power systems, Vol. 19, No. 2, pp 782-787, May 2004.

[6] Ward Jewell, Joseph Warner, James McCalley, Yuan Li, Sree Rama Kumar Yeddannapudi, "Risk-Based Resource Allocation for Distribution System Maintenance", Final Project Report T-24, PSERC Publication 0626, Aug.2006."

[7] Prasad Dongale, " Equipment Condition Assessment and its Importance in Estimation and Prediction of Power System Reliability: MS. Thesis, Available:

www.soar.wichita.edu/dspace/bitsream/10057/2027/1/t08012.pdf

[8] Visvakumar Aravinthan, "Guidelines for Performance Based Distribution Reliability Analysis for Present and Future Grid" Ph.D Dissertation, Available

http://soar.wichita.edu/bitstream/handle/10057/3464/d10014 Aravinthan .pdf?sequence Retrieved on Jan 5, 2010.

[9] Tony Weekes, Tom Molinski and Xin Li, "Risk Assessment Using Transformer Loss of Life Data", IEEE Insulation Magazine, March/April 2004.

[10] "Testing Solid Insulation of Electrical Equipment, Volume 3-1", United States Department of the Interior, Bureau of Reclamation December, 1991.

[11] "IEEE Guide for Partial Discharge Measurement in Liquid- Filled Power Transformers and Shunt Reactors

[12] G. Paul, "Electric Power Equipment Maintenance \& Testing", New York: Mark Dekker, Inc.1998.

[13] "IEEE Guide for Failure Investigation, Documentation and Analysis for Power Transformers and Shunt reactors".

[14] Degang Gan, Fan Liu, Lin Du, Yuming Liu, " Analysis of Water Solubility in Transformer Oil Using Least Square Fitting Method", IEEE International Conference on High Voltage Engineering and Application (ICHVE), 2010 New Orleans, LA.

[15] Y. Du, A. V. Mamishev, B. C. Lesieutre, M. Zahn and S. H. Kang. Moisture Solubility for Differently Conditioned Transformer Oils [J]. IEEE Transactions on Dielectrics and Electrical Insulation, 2001, 8(5): $805-811$

[16] Jens Tepper, Rafael Murillo and Carlos Roy," Dry Type Transformers for the $72.5 \mathrm{KV}$ Voltage Class" 21 st International Conference on Electricity Distribution, Frankfurt, 6-9 June 2011.

[17] I.A.R Gray, "Dissipation Factor, Power Factor and Relative Permittivity Dielectric Constant".

[18] M.E.Honarmand, M.R.Haghifam,H.Doosti Barhagh, J.Talebi,"Maintenance Priorities in Distribution Transformers Based on Importance and Risk",22 $2^{\text {nd }}$ International Conference on Electricity Distribuiton, Stockholm,10-13 June,2013. 